\title{
Frequency Control of Power System with Renewable Power Sources by HVDC Interconnection Line and Battery Considering Energy Balancing
}

\section{Shoyu Onuka ${ }^{*}$, Atsushi Umemura1, Rion Takahashi', Junji Tamura ${ }^{1}$, Atsushi Sakahara ${ }^{2}$, Fumihito Tosaka², Ryosuke Nakamoto ${ }^{2}$}

${ }^{1}$ Department of Electrical and Electronic Engineering, Kitami Institute of Technology, Kitami, Japan

${ }^{2}$ Hokkaido Electric Power Co., Inc., Sapporo, Japan

Email: *tamuraj@kitami-it.ac.jp

How to cite this paper: Onuka, S., Umemura, A., Takahashi, R., Tamura, J., Sakahara, A., Tosaka, F. and Nakamoto, R. (2020) Frequency Control of Power System with Renewable Power Sources by HVDC Interconnection Line and Battery Considering Energy Balancing. Journal of Power and Energy Engineering, 8, 11-24. https://doi.org/10.4236/jpee.2020.84002

Received: March 19, 2020

Accepted: April 18, 2020

Published: April 21, 2020

Copyright $\odot 2020$ by author(s) and Scientific Research Publishing Inc. This work is licensed under the Creative Commons Attribution International License (CC BY 4.0).

http://creativecommons.org/licenses/by/4.0/

\begin{abstract}
Recently, introduction of renewable energy sources like wind power generation and photovoltaic power generation has been increasing from the viewpoint of environmental problems. However, renewable energy power supplies have unstable output due to the influence of weather conditions such as wind speed variations, which may cause fluctuations of voltage and frequency in the power system. This paper proposes fuzzy PD based virtual inertia control system to decrease frequency fluctuations in power system caused by fluctuating output of renewable energy sources. The proposed new method is based on the coordinated control of HVDC interconnection line and battery, and energy balancing control is also incorporated in it. Finally, it is concluded that the proposed system is very effective for suppressing the frequency fluctuations of the power system due to the large-scale wind power generation and solar power generation and also for keeping the energy balancing in the HVDC transmission line.
\end{abstract}

\section{Keywords}

High Voltage Direct Current (HVDC) Transmission, Power System Frequency Control, Coordinated Control, Battery, Renewable Power, Energy Balancing

\section{Introduction}

Many studies have been reported so far about renewable energy systems like 
wind power generation and photovoltaic power generation [1] [2]. The advantage of wind power generation is that the power generation cost is comparatively lower and the energy conversion efficiency is higher than other renewable energy power generations. In addition, there is the advantage in photovoltaic power generation that no noise is appeared in power generation process and the power generation efficiency is about constant regardless of the installed system size. However, the output of these renewable energy power generations may fluctuate due to intermittent characteristics like fluctuations of wind speed and solar radiation intensity. This can cause power system frequency and voltage fluctuations. Therefore, various methods for controlling frequency fluctuations have been investigated [3] [4] [5] [6]. Among them, control method using HVDC interconnection line can be thought to be strong and effective method [7]. This is because the power ratings of actual HVDC interconnection lines are relatively large in most cases and active power flow on the HVDC transmission line can be controlled, in general, easily and quickly based on the AC/DC converter control. This paper proposes fuzzy PD based virtual inertia control system to restrain system frequency fluctuation caused by fluctuating output of renewable energy power supply, which is based on the coordinated control of HVDC interconnection line and battery. In addition, we also propose energy balancing control which is incorporated in the coordinated control system to keep the transmitted energy ( $\mathrm{MWh}$ ) of HVDC transmission line constant at the end of every specified period. Though there have been some reports so far in which power system frequency fluctuations caused by fluctuating output of renewable power sources are controlled by using HVDC interconnection line and battery as stated above, there is almost no one which achieves also the energy balancing control as far as the authors know. Simulation analyses are performed by using PSCAD/EMTDC software to verify the effectiveness of the proposed method.

\section{Model System}

\subsection{Power System Model}

The power system model used in this study and its parameters are shown in Figure 1. It is a modified version of the IEEE standard model with 9 buses [8] which is composed of 3 synchronous generators (SG1, SG2, and SG3). SG1 and SG2 are thermal power plants (SG1: 200 MVA, SG2: 200 MVA), and SG3 is a hydraulic power plant (200 MVA). Moreover, a fixed speed wind turbine squirrel cage induction generator (SCIG) based wind farm (WF, 60 MVA), a PV station (60 MVA), HVDC interconnection line (60 MVA), battery (10 MVA), and three loads (Loads A, B, and C) are connected to the main system [9]. Their conditions are shown in Table 1. The HVDC transmission line is connecting the main modified 9-bus power system (System A) and another large power system (System B, expressed by an infinite bus) and the positive direction of the power flow is from System A to System B. Positive direction of battery power corresponds to charging. 


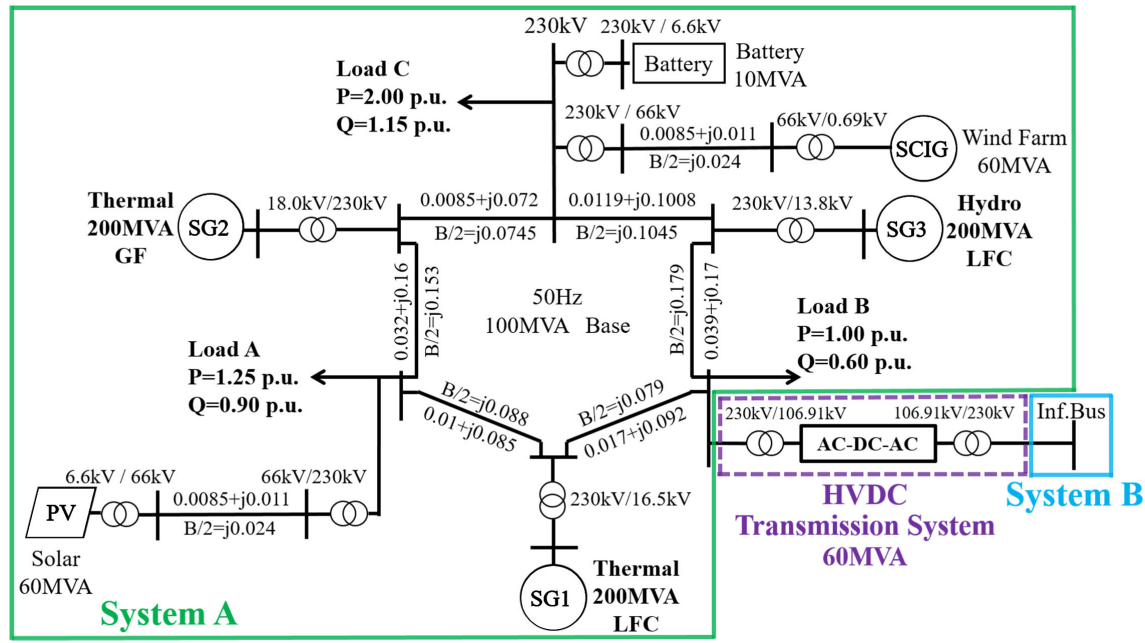

Figure 1. Model system.

Table 1. Conditions of each generator.

\begin{tabular}{cccc}
\hline & Generator & Rated MVA & Frequency Control \\
\hline SG1 & Thermal & $200 \mathrm{MVA}$ & LFC $^{* 1}$ \\
SG2 & Thermal & $200 \mathrm{MVA}$ & $\mathrm{GF}^{*^{2}}$ \\
SG3 & Hydro & $200 \mathrm{MVA}$ & LFC $^{* 1}$ \\
SCIG & Wind Farm & $60 \mathrm{MVA}$ & \\
PV & Solar & $60 \mathrm{MVA}$ & \\
Total Load & & $425 \mathrm{MW}$ & \\
\hline
\end{tabular}

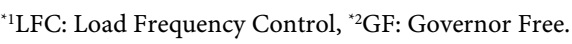

\subsection{Governor Model [10]}

In this study, SG1 and SG3 are operating under load frequency control (LFC) and SG2 is under governor free (GF) operation. Figure 2 and Figure 3 show the thermal governor model used for the thermal power plants (SG1 and SG2) and the hydro governor model used for the hydro power plant (SG3) respectively. The LFC system model is shown in Figure 4, where

Sg: Rotation speed deviation

65M: Load setting (Output reference value)

77M: Load limit $(65 \mathrm{M}+$ rated output $\times$ PLM [\%])

PLM: Governor operating margin [\%]

(A percentage of the rated output)

Pm: Turbine output

Input values of $65 \mathrm{M}$ and $77 \mathrm{M}$ are shown in Table 2. LFC system supplies output command signal to the LFC power plants according to the system frequency deviation. The LFC signal is input to $65 \mathrm{M}$, and then, the output of each LFC power plant is changed. The governor models used in this paper is based on the standard models of the Institute of Electrical Engineers of Japan. 


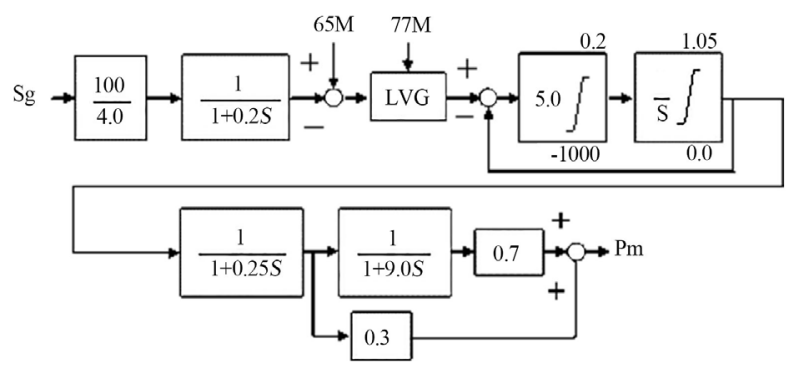

Figure 2. Thermal governor model.

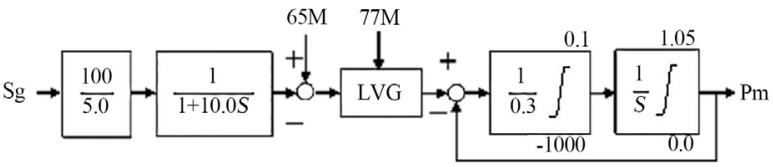

Figure 3. Hydro governor model.

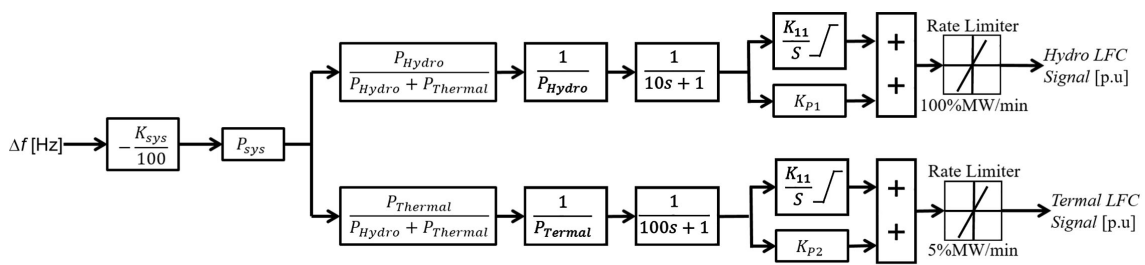

$K_{\text {sys }}:$ Power System Constant [\%MW/Hz] $P_{\text {sys }}:$ Power System Capacity[MW]

$P_{\text {Hydro }}$ :Hydro Power Capacity [MW] $P_{\text {Thermal }}$ :Thermal Power Capacity[MW

Figure 4. LFC model.

Table 2. 65M and 77M of each generator.

\begin{tabular}{ccc}
\hline & $65 \mathrm{M}$ (Load setting) & $77 \mathrm{M}$ (Load limit) \\
\hline SG1 & $\begin{array}{c}\text { Thermal LFC } \\
\text { Signal }\end{array}$ & 1.0 \\
SG2 & 0.8 & 0.84 \\
SG3 & Hydro LFC & 1.0 \\
& Signal & \\
\hline
\end{tabular}

\subsection{Wind Turbine Model [11]}

Wind turbine model used in this paper is shown in Equations (1)-(5).

$$
\begin{gathered}
P_{\omega t b}=(1 / 2) \rho C_{p}(\lambda, \beta) \pi R^{2} V_{w}^{3} \\
C_{p}(\lambda, \beta)=(1 / 2)\left(\Gamma-0.022 \beta^{2}-5.6\right) \mathrm{e}^{-0.17 \Gamma} \\
\lambda=\left(\omega_{w t b} R\right) / V_{w} \\
\Gamma=(R / \lambda)(3600 / 1609), C_{t}(\lambda)=C_{p}(\lambda) / \lambda \\
\tau_{M}=1 / 2 \rho C_{t}(\lambda) \pi R^{3} V_{w} 2
\end{gathered}
$$

where, $P_{\omega t b}$ : wind turbine output $[\mathrm{W}], \lambda$ : tip speed ratio, $R$ : wind turbine radius $[\mathrm{m}], \omega_{W t b}:$ wind turbine angular speed $[\mathrm{rad} / \mathrm{s}], \beta$ : pitch angle $[\mathrm{deg}], V_{w}:$ wind speed $[\mathrm{m} / \mathrm{s}], \rho$ : air density $\left[\mathrm{kg} / \mathrm{m}^{3}\right], C_{p}$ : power coefficient, $C_{t}$ : torque coefficient, 
$\tau_{M}$ : wind turbine torque $[\mathrm{Nm}]$.

\subsection{PV Model [3] [7]}

Figure 5 shows PV model used in this paper. In this study, the PV model is expressed by a simple model using current sources, in which kilowatts data, $\mathrm{P}_{\mathrm{PV}}$ $[\mathrm{kW}]$, is used. Therefore, $\mathrm{PV}$ current $\left(\mathrm{I}_{\mathrm{PV}}\right)$ is calculated from $\mathrm{P}_{\mathrm{PV}}[\mathrm{kW}]$ and $\mathrm{PV}$ voltage, $\mathrm{V}_{\mathrm{PV}}[\mathrm{kV}]$, and the obtained current $\left(\mathrm{I}_{\mathrm{PV}}\right)$ is entered to the current sources.

\subsection{HVDC Model [4] [7] [12]}

Figure 6 shows the Voltage Source Converter (VSC) based HVDC system model used in this study. In this paper, in order to shorten the calculation time of the simulation, VSC-HVDC simple model [9] is used which is expressed by controlled voltage sources instead of IGBT based inverter and rectifier. Reference 8 describes details of this simple model, where comparative analysis is performed between the VSC-HVDC simple model and the detailed VSC-HVDC model using IGBT switching circuits, and finally it is concluded that the accuracy of the VSC-HVDC simple model is high.

Figure 7 shows control system model of System A side converter that converts from three-phase AC to DC voltage. Also Figure 8 shows control system model of System B side inverter that converts the DC voltage to the three-phase AC. The parameters of PI controllers used in Figure 7 and Figure 8 are shown in Table 3.

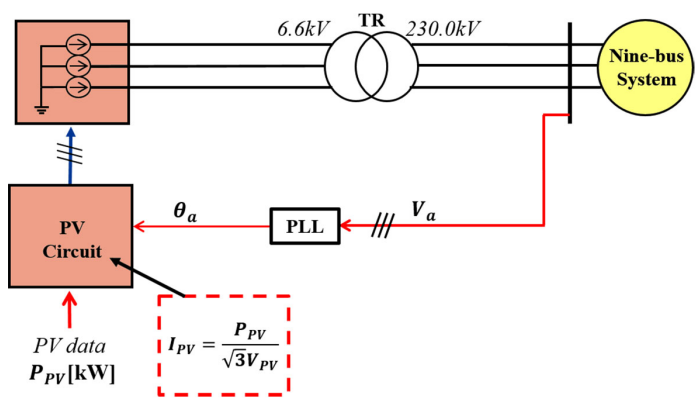

Figure 5. PV model.

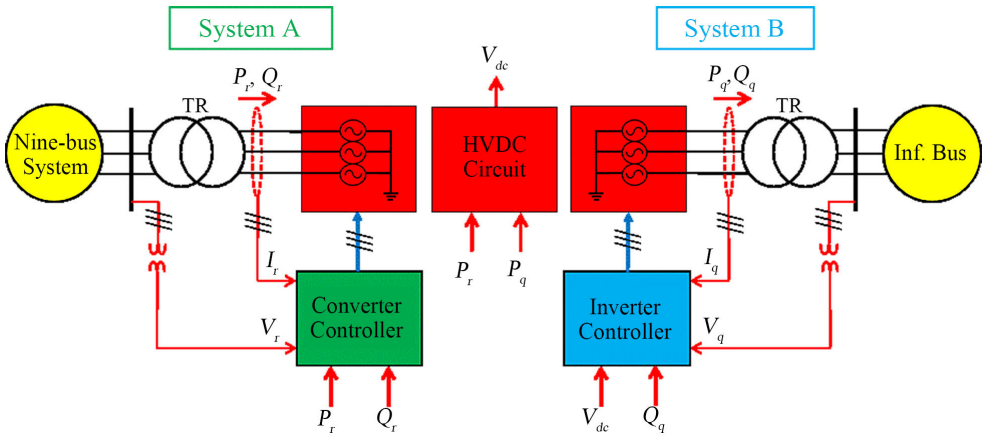

Figure 6. HVDC symple model. 


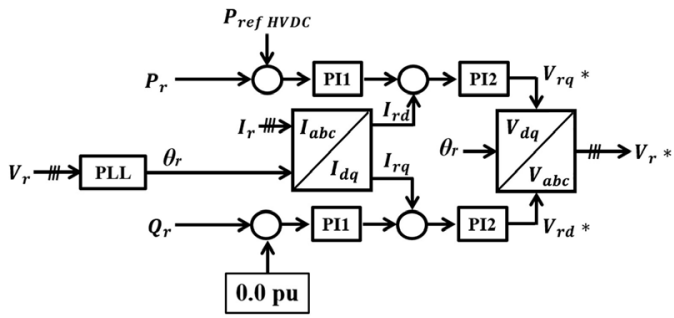

Figure 7. Converter control system.

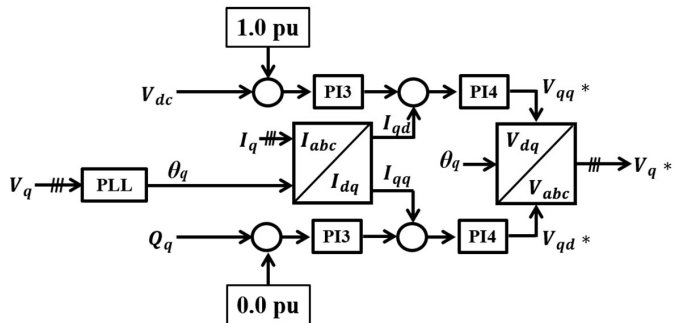

Figure 8. Inverter control system.

Table 3. Parameter of PI controlers.

\begin{tabular}{ccccccc}
\hline & PI1 & PI2 & PI3 & PI4 & PI5 & PI6 \\
\hline Proportional gain & 0.1 & 0.1 & 1.0 & 0.1 & 0.1 & 0.1 \\
Integral Time Constant & 0.01 & 0.2 & 0.1 & 1.0 & 0.02 & 0.2 \\
\hline
\end{tabular}

\subsection{Link Model [4] [7] [12]}

DC-link voltage in the DC-Link circuit of the HVDC model shown in Figure 6 is expressed by Equation (6).

$$
\frac{\mathrm{d} V_{\mathrm{dc}}}{\mathrm{d} t}=\frac{1}{V_{\mathrm{dc}} C_{\mathrm{dc}}}\left(P_{r}-P_{q}\right)
$$

where, $V_{\mathrm{d} c}$ DC voltage, $C_{\mathrm{d} c}$ capacitance of smoothing capacitor in the DC link $(50,000 \mu \mathrm{F}), P_{r}$ : active power of the converter, $P_{q}$ : active power of the inverter, $V_{d c n}$ : rated voltage of the HVDC line $(250 \mathrm{kV})$.

\subsection{Battery Model}

Figure 9 shows battery model used in this paper. The battery model is expressed by a simple model using voltage sources. $Q_{\text {ref_Battery }}$ is fixed at zero. Figure 10 shows the control model of battery converter that converts from three-phase AC to DC voltage. The parameters of PI controllers used in Figure 10 are shown in Table 3.

\section{Proposed Method}

\subsection{Fuzzy PD Control}

Figure 11 and Figure 12 show the fuzzy PD based virtual inertia control systems for the HVDC interconnection line and the battery proposed in this paper. The controller for the HVDC line shown in Figure 11 is composed of PD controller in which D controller is based on FLC (Fuzzy Logic Controller). As differential 
value of the system frequency is used in the FLC, it can generate virtual inertia output component, and thus, it makes it possible to respond quickly to sudden frequency fluctuations. Figure 13 and Table 4 show the membership functions and fuzzy rule base designed for the FLC.

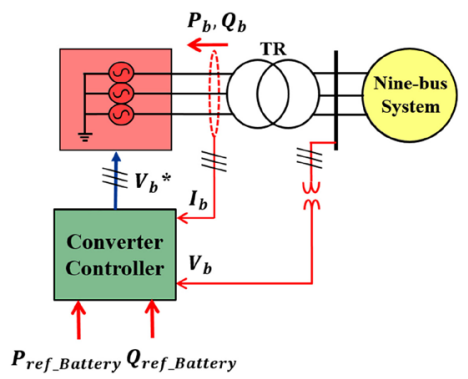

Figure 9. Battery model.

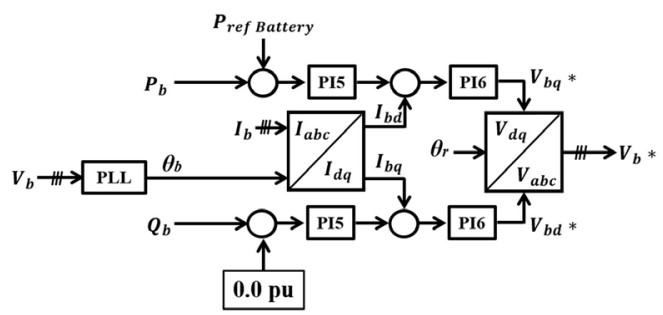

Figure 10. Batterey converterr control system.

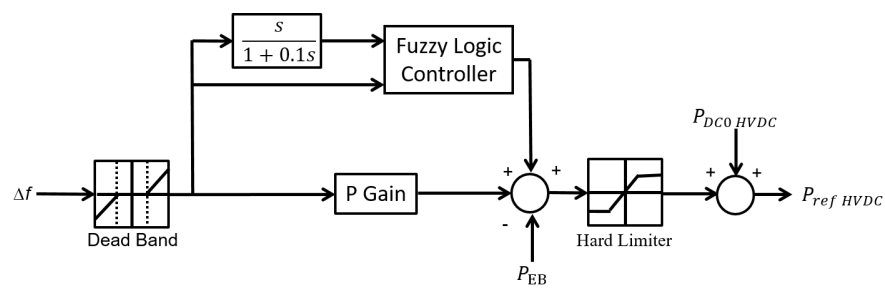

Figure 11. Frequency control with FLC in HVDC line.

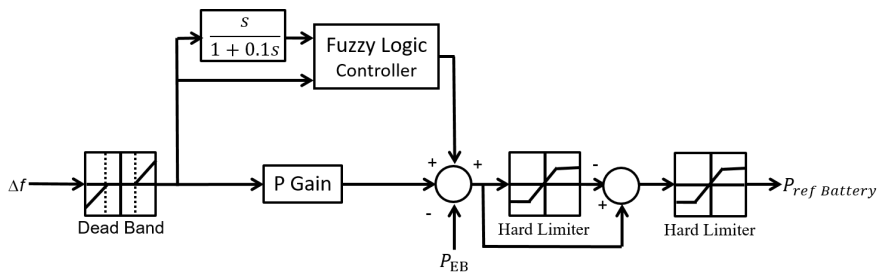

Figure 12. Frequency control with FLC in battery.
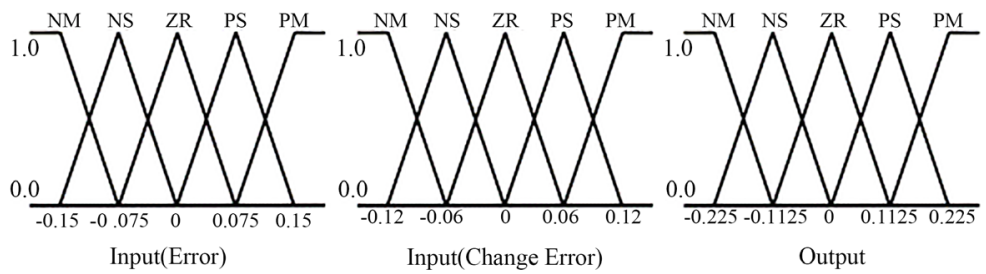

Figure 13. Member ship function. 
Table 4. Fuzzy rule base.

\begin{tabular}{ccccccc}
\hline \multirow{2}{*}{ FLC Signal } & \multicolumn{5}{c}{$\mathrm{d}(\Delta \mathrm{f}) / \mathrm{dt}$} \\
\cline { 3 - 6 } & & PM & PS & ZR & NS & NM \\
\hline \multirow{4}{*}{$\Delta \mathrm{f}$} & PM & PM & PM & PS & PS & ZR \\
& PS & PM & PS & PS & ZR & ZR \\
& ZR & PS & ZR & ZR & ZR & NS \\
& NS & ZR & ZR & NS & NS & NM \\
& NM & ZR & NS & NS & NM & NM \\
\hline
\end{tabular}

\subsection{Coordinated Control}

There is a permissible control range in the transmission power on HVDC interconnection line. This is $\pm 10 \%$ of the rated capacity around the steady state transmission power in Japan under normal situation. Therefore, if the system frequency fluctuation is large so that the reference power of the HVDC line is over the permissible range, the HVDC line cannot control the frequency fluctuation. This paper proposes the coordinated control of HVDC interconnection line and battery. Figure 12 shows the control systems for the battery, where the amount of power exceeding the permissible control range of the HVDC line is calculated, and then, sent to the battery as an output reference value.

\subsection{Energy Balancing Control [13]}

Figure 14 and Figure 15 show the control blocks used for energy balancing control of the HVDC system. The HVDC transmission MWh deviation, $\triangle \mathrm{MWs}$, from System A to System B is calculated by Equation (7).

$$
\Delta \mathrm{MWs}=\int_{t}^{t+\tau}(\mathrm{PDC}-\mathrm{PDC} 0) \mathrm{d} t
$$

where, $P_{D C 0}$ is the reference value for HVDC transmission power, and $P_{D C}$ is the actual transmission power of the HVDC interconnection line. An auxiliary power signal $\mathrm{P}_{\mathrm{EB}}$ for the balancing control is generated by multiplying $\Delta \mathrm{MWs}$ by a gain as shown in Figure 14, and subtracted from the sum of PD control references as shown in Figure 11 and Figure 12. In the control block shown in Figure $15, \Delta \mathrm{MWs}$ is passed through a Variable Dead Band (VDB), and then the auxiliary power signal $P_{\mathrm{EB}}$ is obtained. As shown in Figure 11 and Figure 12, energy balancing control is performed by subtracting the auxiliary power signal $\mathrm{P}_{\mathrm{EB}}$ from the frequency control compensation power signals in the HVDC interconnection line and the storage battery. As described later, two types of gains that increase with time from a certain time $t$ to $t+\tau$ in Equation (7) are used in the control block shown in Figure 14.

\section{Simulation Conditions}

Simulation analyses have been performed in the 6 cases shown in Table 5 to confirm the effectiveness of the proposed method. Figure 16 shows the wind speed data and Figure 17 shows the resulting output of WF used in the simula- 
tion analyses. Figure 18 shows the PV data used in the simulation analyses. Figure 19 shows the total output of WF and PV station. The data used in Figure 16 and Figure 18 were real data measured in Hokkaido, Japan. The simulation time was 1200 seconds and PSCAD/EMTDC software was used for the simulation analyses.

Table 5. Study cases.

\begin{tabular}{|c|c|c|}
\hline & \multicolumn{2}{|l|}{ Control Method } \\
\hline & HVDC Interconnection Line & Battery \\
\hline Case 1 & $\begin{array}{l}\text { Constant power transmission } \\
\text { (fixed at } 30 \mathrm{MW} \text { ) }\end{array}$ & Stand-by (No control) \\
\hline Case 2 & Dead Band control & Stand-by (No control) \\
\hline Case 3 & Fuzzy PD control & Coordinated control \\
\hline Case 4 & $\begin{array}{l}\text { Fuzzy PD control with energy balancing } \\
\text { control (using gain I) }\end{array}$ & $\begin{array}{l}\text { Coordinated control with energy balancing } \\
\text { control (using gain I) }\end{array}$ \\
\hline Case 5 & $\begin{array}{l}\text { Fuzzy PD control with energy balancing } \\
\text { control (using gain II) }\end{array}$ & $\begin{array}{l}\text { Coordinated control with energy balancing } \\
\text { control (using gain II) }\end{array}$ \\
\hline Case 6 & $\begin{array}{l}\text { Fuzzy PD control with energy balancing } \\
\text { control (using Variable Dead Band) }\end{array}$ & $\begin{array}{l}\text { Coordinated control with energy balancing } \\
\text { control (using Variable Dead Band) }\end{array}$ \\
\hline
\end{tabular}

Figure 14. Energy balancing control block using gain.

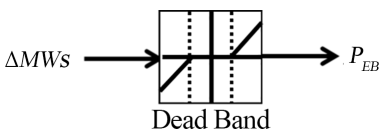

Figure 15. Energy balancing control block using variable dead band.

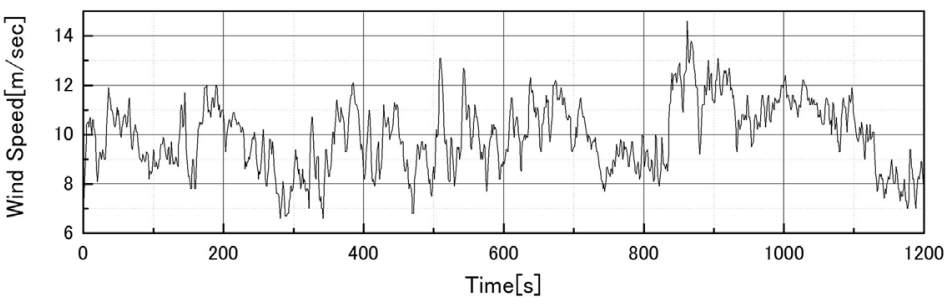

Figure 16. Wind speed data.

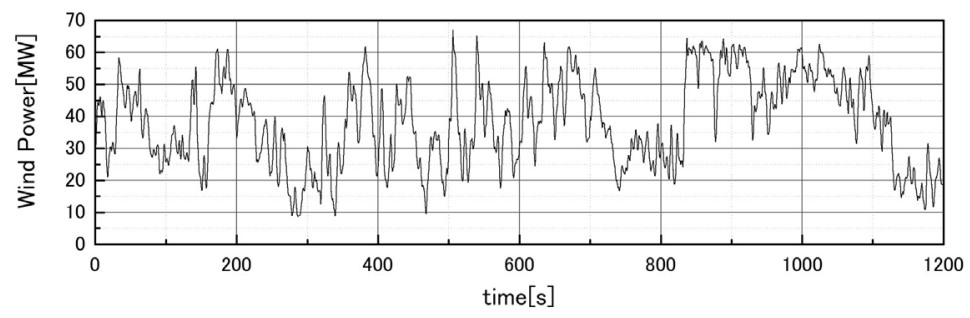

Figure 17. Output of WF. 


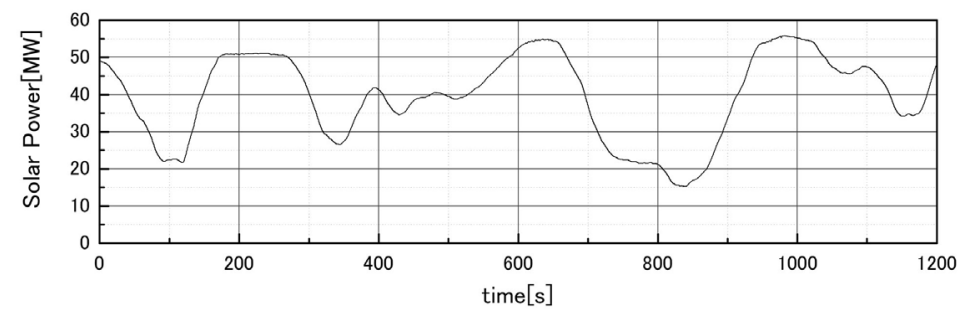

Figure 18. Output of PV station.

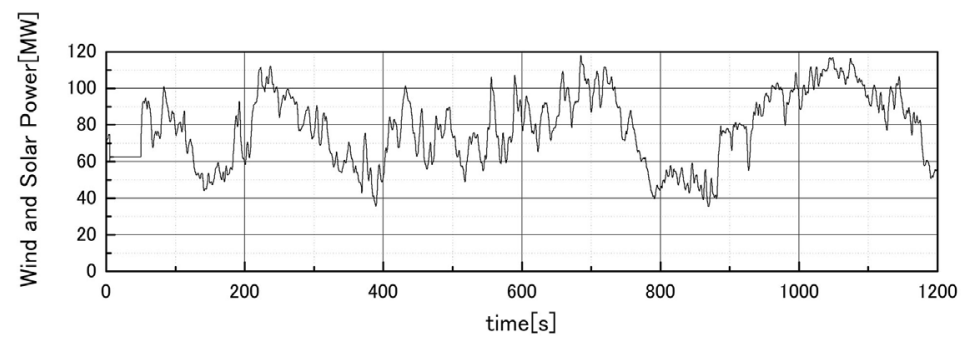

Figure 19. Total output of WF and PV station.

In order to confirm the effectiveness of the proposed method, the energy balancing control for 10 minutes is performed twice in the simulation for 1200 seconds, i.e., 0 to 600 seconds and 600 to 1200 seconds. As shown in Figure 20, two types of gains are used in the control block shown in Figure 14, where gain I increases linearly from 0 at $\mathrm{t}=300$ seconds to 1.0 at $\mathrm{t}=600$ seconds and gain II increases linearly from 0 at $\mathrm{t}=550$ seconds to 1.0 at $\mathrm{t}=600$ seconds. On the other hand, Variable Dead Band is used in the control block shown in Figure 15, of which threshold value becomes gradually narrower from \pm 6 [MWs] at 0 seconds to 0 [MWs] at 600 seconds as shown in Figure 21. In Figure 21, the white area is dead zone, and if $\Delta \mathrm{MWs}$ exceeds the pink line, which is the threshold line, the energy balancing control is activated. Interval of the integration of Equation (7) for $\Delta \mathrm{MWs}$ is set to $[0,600]$.

\section{Simulation Results}

The simulation results are shown in Figures 22-25 and Table 6. Figure 22 shows the frequency responses of System A in the 6 cases. Figure 23 shows the HVDC transmission line power. Figure 24 shows the battery power (positive value corresponds to charging). Figure 25 shows the transmitted energy deviation, $\Delta \mathrm{MWs}$, obtained from Equation (7). Table 6 shows the maximum deviation and the standard deviation of the frequency fluctuation of System A.

Comparing Cases 1 to 6 in Figure 22 and Table 6, it is seen that the maximum frequency deviation in Case 1 exceeds the permissible range, $\pm 0.2 \mathrm{~Hz}$, which is the standard permissible range of power system frequency fluctuations in Japan. This is because the frequency control is not performed in Case 1. The frequency deviation is largest in this case. Next, the dead band control is performed in Case 2. However, since only the control by the HVDC interconnection line is performed in this case, the frequency fluctuation is also large and the 
Table 6. Maximum and standard deviation of system frequency.

\begin{tabular}{ccccccc}
\hline & Case 1 & Case 2 & Case 3 & Case 4 & Case 5 & Case 6 \\
\hline $\begin{array}{c}\text { Maximum Frequency } \\
\text { Deviation }+\Delta f[\mathrm{~Hz}]\end{array}$ & 0.4575 & 0.2974 & 0.1949 & 0.2010 & 0.1949 & 0.1976 \\
$\begin{array}{c}\text { Maximum Frequency } \\
\text { Deviation }-\Delta f[\mathrm{~Hz}]\end{array}$ & -0.5514 & -0.1906 & -0.1484 & -0.1886 & -0.1484 & -0.1534 \\
Standard Deviation $[\mathrm{Hz}]$ & 0.09696 & 0.05606 & 0.05316 & 0.05576 & 0.05377 & 0.05377
\end{tabular}

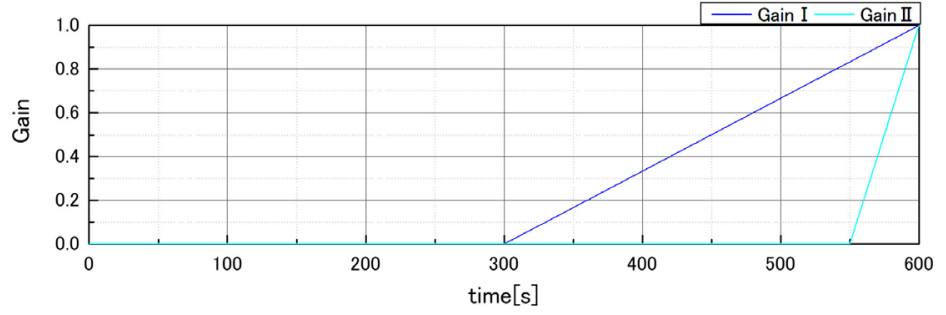

Figure 20. Gain used in energy balancing control block (blue line: gain I, light blue line: gain II).

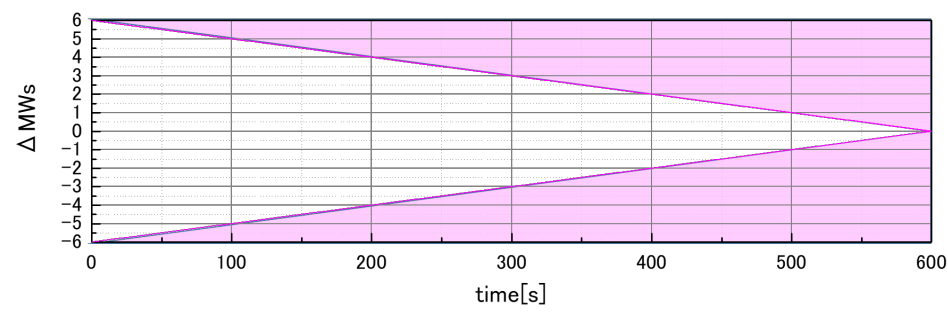

Figure 21. Variable Dead Band threshold value used in energy balancing control block.

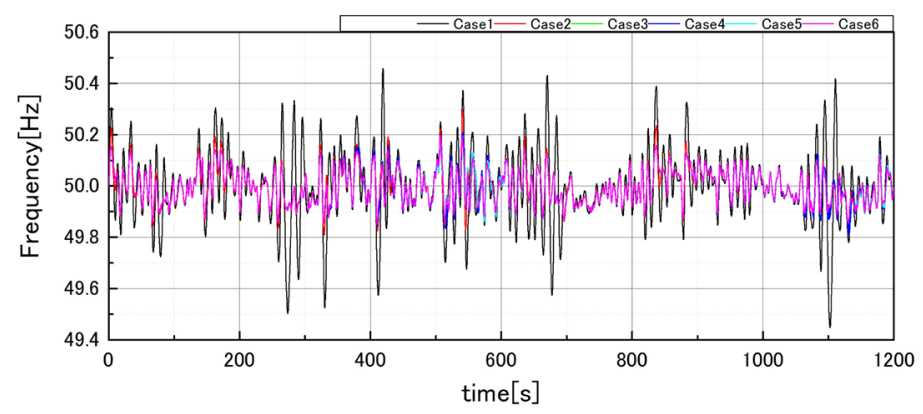

Figure 22. Frequency of System A.

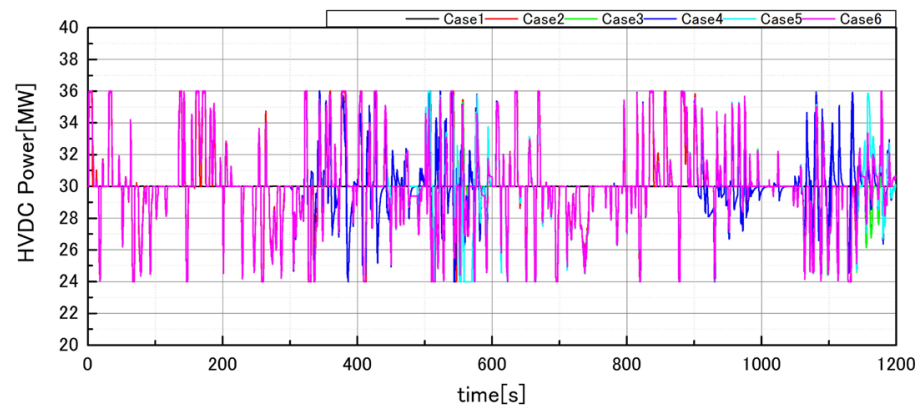

Figure 23. HVDC transmission line power. 


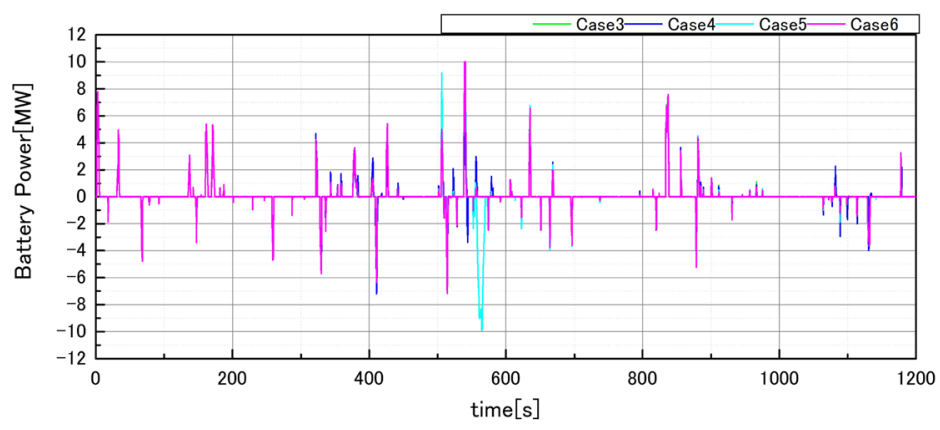

Figure 24. Battery power.

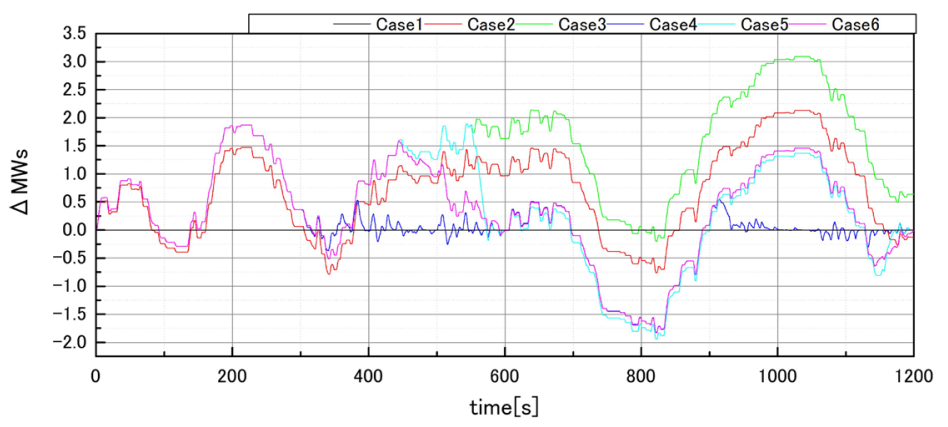

Figure 25. Electric energy deviation.

fluctuation in the positive side exceeds $0.2 \mathrm{~Hz}$. This is because the variations of HVDC transmission line power for controlling the system frequency fluctuations reach the permissible control range in the transmission power on HVDC interconnection line. The best results are obtained in Case 3 for both the maximum and standard deviations of the system frequency, because the coordinated control of HVDC interconnection line and battery is performed in this case. However, it is seen from Figure 25 that the transmitted energy deviation, $\Delta$ MWs, does not become 0 at 600 and 1200 seconds, because the energy balancing control for 10 minutes is not performed in this case. On the other hand, $\Delta$ MWs becomes 0 at 600 and 1200 seconds in Cases 4, 5, and 6 as can be seen from Figure 25, because the energy balancing control is performed in these cases. This confirms that the proposed energy balancing control is very effective for keeping the transmitted energy balance. In addition, it is also seen from Table 6 that the performances about the system frequency deviations in these 3 cases are worse than that in Case 3. This is because the energy balancing control is also performed in Cases 4, 5 and 6. However the performances in Cases 5 and 6 are almost the same level as that in Case 3, and the best results are obtained in Case 5 where gain II shown in Figure 20 is used in the energy balancing control block shown in Figure 14.

As a result, it can be concluded that the coordinated control of HVDC interconnection line and battery in Case 5 is the most effective method for achieving both the system frequency control and the energy balancing control in the HVDC transmission line. As the proposed coordinated system (Case 5) can con- 
trol well power system frequency fluctuations caused by fluctuating output of renewable power sources as well as can achieve the energy balancing in the HVDC interconnection line, it has original and significant values from a point of view of stabilization of power systems with renewable power sources installed.

\section{Conclusions}

In this paper, a coordinated control method of HVDC interconnection line and battery is proposed in order to suppress the frequency fluctuations of the power system where wind farm and solar power station are installed, in which the control system is designed based on the fuzzy PD based virtual inertia controller and the energy balancing control in the HVDC transmission line is also considered.

Simulation analyses show the effectiveness of the proposed method. As a result, it is concluded that the system proposed in this paper is very effective for suppressing the frequency fluctuations of the power system caused by the large-scale introduction of wind power generation and solar power generation and also for keeping the energy balancing in the HVDC transmission line.

\section{Conflicts of Interest}

The authors declare no conflicts of interest regarding the publication of this paper.

\section{References}

[1] Rahman, M.L., Oka, S. and Shirai, Y. (2010) Hybrid Power Generation System Using Offshore-Wind Turbine and Tidal Turbine for Power Fluctuation Compensation (HOT-PC). IEEE Transactions on Sustainable Energy, 1, 92-98. https://doi.org/10.1109/TSTE.2010.2050347

[2] Lin, F., Lu, K., Ke, T., Yang, B. and Chang, Y. (2015) Reactive Power Control of Three-Phase Grid-Connected PV System During Grid Faults Using Takagi-Sugeno-Kang Probabilistic Fuzzy Neural Network Control. IEEE Transactions on Industrial Electronics, 62, 5516-5528. https://doi.org/10.1109/TIE.2015.2407851

[3] Tada, K., Umemura, A., Takahashi, R., Tamura, J., Matsumura, Y., Yamaguchi, D., Kudo, H., Niiyama, M. and Taki, Y. (2017) Frequency Control of Power System with Solar and Wind Power Stations Installed by Flow Control of HVDC Interconnection Line. International Conference on Electrical Machines and Systems, ID621. https://doi.org/10.1109/ICEMS.2017.8056355

[4] Sato, T., Umemura, A., Takahashi, R. and Tamura, J. (2017) Frequency Control of Power System with Large Scale Wind Farm Installed by Using HVDC Transmission System. IEEE PES PowerTech, Manchester, United Kingdom, 2017. https://doi.org/10.1109/PTC.2017.7979749

[5] Ono, T. and Arai, J. (2012) Frequency Control with Dead Band Characteristic of Battery Energy Storage System for Power System Including Large Amount of Wind Power Generation. IEEJ Transaction on Power and Energy, 132, 709-717. (In Japanese) https://doi.org/10.1541/ieejpes.132.709

[6] Wu, Z., Gao, D.W., Zhang, H., Yan, S. and Wang, X. (2017) Coordinated Control Strategy of Battery Energy Storage System and PMSG-WTG to Enhance System Frequency Regulation Capability. IEEE Transactions on Sustainable Energy, 8, 
1330-1343. https://doi.org/10.1109/TSTE.2017.2679716

[7] Tada, K., Sato, T., Umemura, A., Takahashi, R., Tamura, J., Matsumura, Y., Taguchi, T. and Yamada, A. (2018) Frequency Control of Power System with Solar and Wind Power Stations by Using Frequency Band Control and Deadband Control of HVDC Interconnection Line. Journal of Power and Energy Engineering, 6, 48-63. https://doi.org/10.4236/jpee.2018.69007

[8] Anderson, P.M. and Found, A.A. (1994) Power System Control and Stability. IEEE Press, New York.

[9] Rosyadi, M., Umemura, A., Takahashi, R., Tamura, J., Uchiyama, N. and Ide, K. (2015) Simplified Model of Variable Speed Wind Turbine Generator for Dynamic Simulation Analysis. IEEJ Transactions on Power System Power and Energy, 135, 538-549. https://doi.org/10.1541/ieejpes.135.538

[10] Liu, J., Rosyadi, M., Umemura, A., Takahashi, R. and Tamura, J. (2014) A Control Method of Permanent Magnet Wind Generators in Grid Connected Wind Farm to Damp Load Frequency Oscillation. IEEJ Transactions on Power and Energy, 134, 393-398. https://doi.org/10.1541/ieejpes.134.393

[11] Wasynczuk, O., Man, D.T. and Sullivan, J.P. (1981) Dynamic Behavior of a Class of Wind Turbine Generators during Randon Wind Fluctuations. IEEE Transactions on Power Apparatus and System, PAS-100, 2837-2845. https://doi.org/10.1109/TPAS.1981.316400

[12] Jahan, E., Hazari, M.R., Rosyadi, M., Umemura, A., Takahashi, R. and Tamura, J. (2017) Simplified Model of HVDC Transmission System Connecting Offshore Wind Farm to Onshore Grid. IEEE PES PowerTech, Manchester 2017, No. 51. https://doi.org/10.1109/PTC.2017.7981049

[13] Tada, K., Umemura, A., Takahashi, R., Tamura, J., Matsumura, Y., Yamaguchi, D., Kudo, H., Niiyama, M. and Taki, Y. (2019) Frequency Control of Power System with Renewable Power Sources by HVDC Interconnection Line Considering Energy Balancing. IEEJ Transactions on Power and Energy, 139, 163-169. (in Japanese) https://doi.org/10.1541/ieejpes.139.163 